Association for Information Systems AIS Electronic Library (AISeL)

AMCIS 1998 Proceedings

Americas Conference on Information Systems

(AMCIS)

December 1998

\title{
Global Enterprise Resource Planning Implementation
}

Christopher Holland

Manchester Business School

Ben Light

Manchester Business School

Nicola Gibson

Manchester Business School

Follow this and additional works at: http://aisel.aisnet.org/amcis 1998

\section{Recommended Citation}

Holland, Christopher; Light, Ben; and Gibson, Nicola, "Global Enterprise Resource Planning Implementation" (1998). AMCIS 1998 Proceedings. 142.

http://aisel.aisnet.org/amcis1998/142

This material is brought to you by the Americas Conference on Information Systems (AMCIS) at AIS Electronic Library (AISeL). It has been accepted for inclusion in AMCIS 1998 Proceedings by an authorized administrator of AIS Electronic Library (AISeL). For more information, please contact elibrary@aisnet.org. 


\title{
Global Enterprise Resource Planning Implementation
}

\author{
Chris Holland \\ Ben Light \\ Nicola Gibson \\ Manchester Business School
}

\begin{abstract}
Enterprise Resource Planning (ERP) solutions are a popular method for enabling the business processes required to compete in advent of globalisation. The textiles industry's global customer base has specific cost and availability needs that are forcing suppliers to become more sophisticated in the management of manufacturing and where this is becoming increasingly dependent upon the successful choice and implementation of IT. Case evidence highlights how globalisation pressured a firm to align organisation structures with business processes and business strategy with IT strategy in order to compete. It also shows the complexity that the choice of an ERP solution brings to implementation.
\end{abstract}

\section{Introduction}

Organisations are facing an increasingly competitive global market. Levitt (1983) proposes that there is a convergence in commonality and that standardised global consumer products are key to a firms competitiveness. He believes that the days of national and regional preferences are gone. Conversely, Ohame (1989) states that tastes do not form an amorphous mass of universal appeal where the localisation of products is defunct. He proposes firms take an equidistant view of the global market which recognises its heterogeneity. Both ideas are plausible and the resulting strategic response will often require new ways of work and new organisational forms which are underpinned by information systems. A homogeneous or heterogeneous view of the market will however, impact upon the management of global information systems (Ives and Jarvenpaa 1991). In either case, legacy information systems may not be able to meet the needs of the business and the resulting misalignment may require a new IT infrastructure. It is widely cited that business and IT strategies should be aligned (Reich and Benbasat 1996, Boynton et al 1992, Henderson and Venkatraman 1991). Moreover, Ives and Jarvenpaa (1991) state that the misalignment of IT and global business strategy can severely affect a firm's global aspirations. According to Price Waterhouse (1996) by the year 2000 approximately $80 \%$ of firms will be implementing standard package solutions in order to overcome the problems of their legacy systems and increase global competitiveness. This paper analyses the strategic context and implementation of a global ERP project in "Threads" a multinational textiles company.

\section{The Need For Change}

Threads is comprised of a consumer division and an industrial division. The consumer division was targeted at domestic users, a market which has declined since the 1970's as the economy of domestic garment production has reduced. It has therefore been developed into a supplier of craft products such as embroidery pictures. The industrial business deals mainly with mass production garment manufacturers. This market has grown as have the associated pressures of cost and availability. Threads industrial customers operate in a labour intensive business where costs and lead time are key business pressures. Trade tends to follow where labour costs are the least expensive and products are readily available. Subsequently, Threads has to maintain low cost levels whilst ensuring timely availability on a world-wide basis.

Threads had profitability problems in Europe due to excess and sub-scale capacity - the national industrial firms were manufacturing for fluctuating local markets and were not taking advantage of economies of scale. Threads needed to reduce the overheads of its European operations to make them comparable with those it had in the United States. It also wanted to empower local marketing staff to make better more informed decisions. The turning point came when Threads wanted to close a manufacturing plant and realised that it could not do this as it would be impossible to provide an equivalent level of service to its customers due to its legacy information systems.

\section{Threads Legacy Information Systems}

Threads was comprised of national autonomous business units having disparate IT systems which the Finance and Technology Director described as "fragmented at best". In Europe alone there were 65 different systems in operation and most were nearing the end of their useful lives. The systems were bespoke or heavily modified packages that were not supported by the IT vendors. This meant that in addition to the complexity resulting from the variety of different systems, the level of entropy within each system was high. IT spend was also very reflecting partially a pervasive penny pinching attitude throughout the industry due to the pressures upon it and the fragmented and low level nature of the IT structure which caused it to be viewed 
as an expense rather than a strategic opportunity. The Finance and Technology Director felt that the best thing that Threads could do with the systems was to "toss them out of the window".

Threads had national organisation structures typical of a geographically dispersed product based company (see Figure 1). These were hierarchical in nature and aimed to control costs and employee resources on a national basis. The legacy structures and processes could not effectively meet the new global outlook of the business. The disparate cultures of the national business units also exacerbated the organisational structure and business process difficulties. A senior director at Threads said that, "sites were run by Managing Directors who acted like Barons of their domains". The business was also operating in a turbulent market which made for a feeling of unease amongst the employees. Any change therefore had to be handled very carefully.

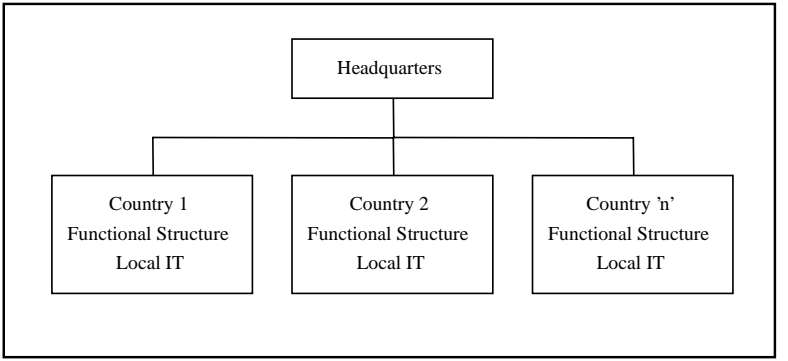

Figure 1. The Original Organisation Structure and Supporting IT

\section{The Strategic Review}

In 1993 a strategic review commenced based upon developing a pan-European system which would integrate the industrial European firms. In 1996, the systems scope was extended to include all companies throughout Threads in order to maximise the benefits of international operations which meant implementing a common global system. Threads realised that both the industrial and crafts businesses needed to be integrated. This brought added complexity because Threads recognised that it would be imposing the system upon the crafts business and that there were strong differences in the ways that it and the industrial business operated. The strategic review took three years due to senior management changes and the expansion of the scope of the project. This led to a more complex evaluation of system requirements. The intended organisation structure and supporting global ERP system is shown in Figure 2. The system would improve customer links to stock and production information across Europe. It would also facilitate the rationalisation of manufacturing and administrative overheads particularly in non-value added areas. For example, in Europe there were 30 accounting systems in comparison to one in the United States.

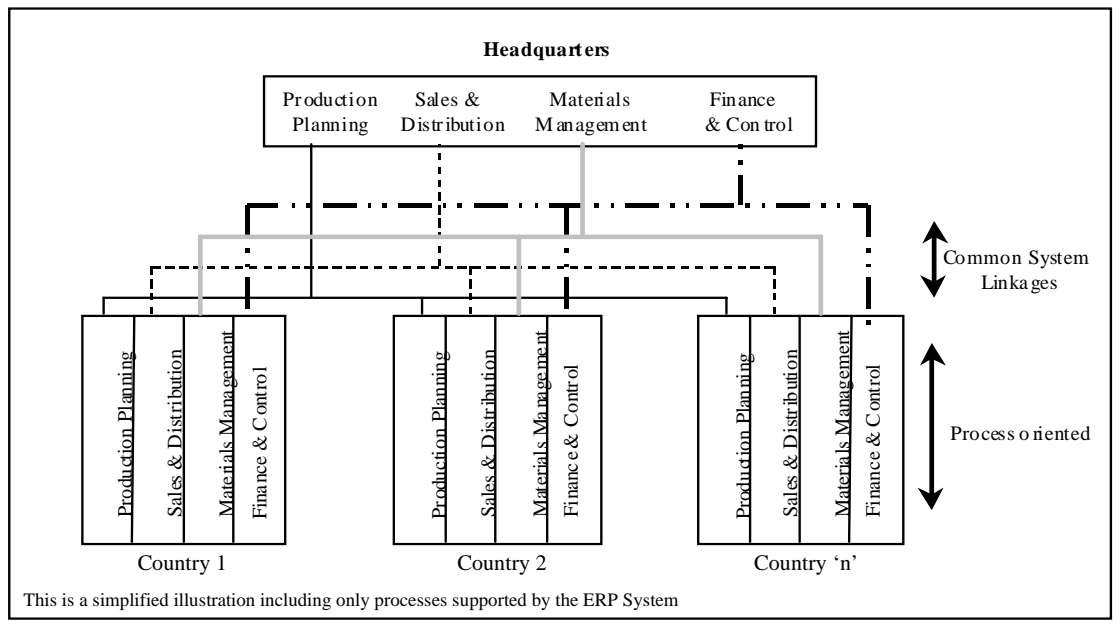

Figure 2. The Intended Organisation Structure and Supporting IT

\section{Implementation}

At first Threads felt that, "Whatever we did would be wrong. Therefore we just had to get something in, use it for a few years and then throw it away" (Threads Senior Director). However, the group came to realise that factors such as the systems criticality to the business, its roll out period, and its cost meant that this philosophy was not viable. Threads optimised internal and external expertise by entering into a partnership with consultants who aided change management and systems development. To complement this, the 'top people' from throughout the business were brought into the project. The project team has grown significantly since implementation began. It

originally totalled a mix of 30 Threads staff and consultants and now stands at approximately 72 . The project has experienced delays due to the high turnover of consulting staff. A Project Manager was appointed in April 1996 and Threads also appointed a Change Manager, the existing Personnel Director. The Change Manger felt it was important that a conscious effort to manage change was essential due to the projects scale and scope. He stated, "The group has taken the decision to change the organisation from within in an incremental way rather than attempt to transform the company overnight." According to the Change Manager the consultants had their own model of change management which he viewed as mechanical and quite forceful. The Change Manager thought that the Threads context needed more sensitivity and consequently change had to come from within the organisation in a less mechanistic and dramatic way. The latter approach has been adopted but the transformation of the company is still the ultimate aim.

The project assessment and planning phase took place from January until March 1997. This involved holding workshops with 150 staff which examined fairly generic business processes in order to ensure relevance to those involved and encourage ownership and participation. Thirty business processes were identified and understood in terms of their inputs, outputs, critical success factors and dependencies. The idea was to understand how each process worked and the national variances. Business events were then examined which contained more detail than the business processes. This led to the development of a "big 
picture' solution. The Project Manager, said that "it is like building a house, you have to get the foundations right... this wasn't the time to start worrying about the carpets and curtains."

The configuration of the ERP system and the documenting of activities in processes then began. The project team worked in four business process areas corresponding with the package - Production Planning, Sales and Distribution, Materials Management and Finance and Control. The business events were configured through the ERP system. The ERP system was used to drive through consensus in this area but this was problematic. Some areas within the individual businesses, such as sales and distribution, were more similar and consequently easier than others, such as production planning or warehousing where there was no one way of doing things across the national entities. However, the Project Manager felt that the group would be well placed to avoid having legacy problems in the future by developing core process modules and only allowing essential national business idiosyncrasies. European sites were fully configured in the common ERP package, on a common platform and using the same consultancies. Core global processes are to be developed in the same package whilst peripheral processes can be developed in others. Global sites also have a choice in terms of hardware provider and implementation partner. However, a senior director felt that, "sites would have to make a strong case to defer from the preferred IT platform and implementation partners."

The project team have already identified and are attempting to deal with potential problems within processes due to the differences amongst the national businesses and is performing essential local modifications as necessary. System testing started in November 1997 and involves users from pilot sites providing feedback on the intended system. The team is also developing training material and an on-line help file. It is hoped that the system will begin to go live in May 1998. This will involve 10 sites of the industrial business in the United Kingdom. Sites in central Europe and the crafts business will be the next to follow in the fourth quarter of 1998.

\section{The Transformation of Threads}

Threads is undergoing a transformation which will reduce overheads and increase customer responsiveness and customer service levels throughout the business. This has been facilitated by implementing a common ERP system. Threads approach to managing IT corresponds to the organisational transformation that has taken place. The IT infrastructure has changed from one that was fragmented and unresponsive to business requirements into one that exploits the scale of the European organisation whilst retaining local responsiveness. This transformation has been extremely difficult and complex to manage because of the need to align business processes with the ERP system, the globalisation of the organisations structure and the growth in the scale of the project from its original specification. Consequently, the cost of developing and implementing the common global system has risen dramatically over the life of the project. Current estimates of the project costs are 5 times higher than original estimates, reflecting both the learning curve of the project and its greater scope. Additional significant reorganisation costs are also contemplated to unlock the full potential of the project.

\section{Acknowledgements}

The authors would like to thank the Engineering And Physical Sciences Research Council who have supported the research reported in this paper under the Systems Engineering For Business Process Change Programme of research.

\section{References}

Boynton A.C. Jacobs, G.C. and Zmud R.W. (1992) “Whose responsibility is IT management?", Sloan Management Review, Summer, pp. 32-38.

Ives B. And Jarvenpaa S.L. (1991) “Applications Of Global Information Technology: Key Issues For Management”, MIS Quarterly, pp. 32-49.

Levitt T. (1983) “The Globalization Of Markets”, Harvard Business Review, May-June, pp. 92-102.

Ohame K. (1989) “Managing In A Borderless World”, Harvard Business Review, May-June, pp. 152-161.

Henderson J.C. and Venkatraman N. (1991) "Understanding Strategic Alignment”, Business Quarterly, Winter, pp.72-78.

Price Waterhouse (1996) Price Waterhouse Information Technology Review 1995/1996, Price Waterhouse, London.

Reich B.H. and Benbasat I. (1996) "Measuring the Linkage between Business and Information Technology Objectives", MIS Quarterly, May, pp. 55-81. 